\title{
Factors associated with high prevalence of coughs, colds and fever among urban slum dwellers in Dhaka, Bangladesh
}

\author{
Arina Zanuzdana ${ }^{1}$, Md. Mobarak H. Khan ${ }^{2}$, Johanna Katharina Brinkel ${ }^{3}$, Alexander Kraemer ${ }^{4}$ \\ ${ }^{1}$ Doctoral candidate; ${ }^{2}$ Assistant Professor; ${ }^{4}$ Professor and Head; Department of Public Health Medicine, School of Public Health, \\ University of Bielefeld, Germany. ${ }^{3}$ Doctoral student, School of Public Health, Department of Biological, Environmental and \\ Occupational Health Sciences, University of Ghana, Ghana.
}

\begin{abstract}
While adverse housing is commonly associated with high respiratory morbidity in urban slum areas, data on prevalence of common respiratory symptoms among adults in urban slums in Bangladesh is limited. We compared the frequency of common respiratory symptoms among men and women in relation to individual socio-demographic and household characteristics using methods of descriptive and analytic epidemiology. Cross-sectional data from 1892 adult respondents collected in the baseline study in 2009 in nine urban slum areas of Dhaka were used. Three month prevalence of coughs and colds was $21.5 \%(\mathrm{n}=1,893)$. Women were more vulnerable to respiratory symptoms in relation to the frequent exposure to stagnant water bodies near the house (OR: $4.44 ; 95 \%$ CI: 2.49 7.93) and waste disposal (OR: 3.57; 95\% CI: 1.37-9.31). Practice of smoking inside dwelling increased the likelihood of having respiratory symptoms for both sexes. Recurrent contact or exposure to stagnant water and unhygienic waste management appeared to be the strongest factors associated with respiratory symptoms, particularly among women. This finding underlines the significance of the improvement of housing quality in slum areas affected by stagnation of water and improper waste management as well as the need for public health intervention to minimize the risk of diseases associated with these factors.
\end{abstract}

Keywords: Cough, Fever, Respiratory Symptoms, Urban Slums, Bangladesh.

\section{Introduction}

People living in highly urbanized areas are exposed to multiple risk factors for respiratory diseases, ranging from indoor air pollution and passive smoking to inhalation of dangerous organic and inorganic compounds at the work place. ${ }^{1-6}$ Slum areas are especially recognized as focal points of different communicable diseases. ${ }^{7-9}$ During rainy seasons and winters, fevers, colds and coughs, as well as diarrhea, cholera, asthma and other illnesses are common among the slum dwellers of Bangladesh. According to the Bangladesh Bureau of Statistics, fevers with colds and coughs are among the main causes of morbidity in the Bangladeshi population ${ }^{10}$ and acute respiratory infections represent the main cause of mortality and morbidity among children. ${ }^{11}$ Commonly, respondents in surveys in urban slums do not have knowledge about the causes and symptoms of their diseases, but in case of fever and coughs and colds their knowledge is more reliable. ${ }^{12}$ Adverse living conditions in slum areas, crowding and poor housing sanitation, provisional building materials, lack of environmental hygiene as well as high levels of indoor air pollution have a dramatic impact on the overall health of slum dwellers, especially in relation to the frequency of respiratory symptoms and other diseases. ${ }^{9,13-16}$ In the present study we aimed to identify the major factors associated with coughs, colds and fever among adult residents of urban slums in Dhaka, allowing for gender differences.

\section{Practice Points}

- People living in highly urbanized areas are exposed to multiple risk factors for respiratory diseases.

- Coughs, colds and fever are highly frequent among urban slum dwellers in Dhaka, Bangladesh.

- Repeated exposure to stagnant water is a prominent factor associated with respiratory symptoms in urban slum areas along with unhygienic garbage disposal and smoking inside the home.

- Adverse living conditions and stagnant water have a bigger impact on women's respiratory health compared to men.

- Prevention of water stagnation in heavily affected urban slum areas as a part of public health intervention is likely to have a significant positive impact on the health of urban slum dwellers.

Correspondence: Arina Zanuzdana, Doctoral candidate, University of Bielefeld, School of Public Health, Department of Public Health Medicine (AG2), Universitaetsstrasse 25, 33615 Bielefeld, Germany. E-mail: azanuzdana@uni-bielefeld.de. 


\section{Materials and methods}

\section{Study population and sampling strategy}

In this study we used data from a cross-sectional baseline survey for a cohort study conducted in urban slums in 2009 in Dhaka, Bangladesh. In 2009, 1,938 adults were systematically selected from nine slum areas in Dhaka in order to gain information about the health of the population living in urban slum areas. We used a systematic sampling approach to select our households for interview. First, we used slum information (e.g. name of the slum, the number of households, the estimated population, the area of slum) provided by the Centre for Urban Studies (CUS). ${ }^{17}$ In order to select only large slums, we applied two inclusion criteria: a minimum of 500 households in a slum and a minimum land size of six acres. In the units with more than one slum we randomly selected one of these slums. Next, our research team prepared an individual household map for each slum and marked all the households in it (families). Each household was provided with one unique identification number. Global positioning system (GPS) was also used to show and record the location of each interviewed household. Finally, we verified the estimated number of families within each slum with the help of local residents and community leaders. Each household sketch map with numbers was considered as the sampling frame of the study. ${ }^{18,19}$ We estimated the representative sample of families for each slum using the statistical formulae (not given here) proposed by Bartlett et al. ${ }^{20}$ A 95\% confidence level (i.e. alpha $=0.05$ ) and an acceptable error margin of $\mathrm{d}=6 \%$ were applied. Since it was not possible to conduct a pilot study for estimating the prevalence of outcomes of interest (p), we chose the recommended value of $p=0.50$. We calculated the sampling rate ' $r$ ' by dividing the number of families in the slum by the calculated sample size. We then interviewed an adult in every ' $\mathrm{r}$ 'th, household.

For the survey one person (the oldest present person at the time of interview) from each household was selected for an interview. This person provided the information on her-/himself and answered questions regarding other family members. The baseline data analysed in this paper is based on individual data obtained from the survey. An informed consent was obtained from each participant.

Use of local language terms for colds, coughs and fever There are cultural differences in understanding of what colds and coughs are. "Cold" in the Bangladeshi population is known to be interpreted as an exposure to cold weather, air or floor, and is associated with a building-up of mucus. ${ }^{22,23}$ The local terms used for cough, cold and fever in Bangladesh are kashi, thanda and jor, respectively. ${ }^{22,23}$

\section{Dependent and independent variable}

Every respondent was asked to report whether s/he suffered from "Fever" or "Cough and cold" in the preceding three months. The main outcome was "Cough and cold" and additionally one more outcome was the combined variable for all three symptoms "Fever, cough and cold". We have excluded those few respondents who also reported tuberculosis, asthma or allergy in the preceding three months.

Individual socio-demographic and health variables and household-level characteristics were selected as independent variables, which according to our hypothesis could be associated with the respiratory symptoms we studied. We have analysed several factors which we assumed to be associated either with respiratory symptoms of infectious or non-infectious origin. The number of persons living with the respondent (or crowding) and the means of garbage disposal (hygienic or non-hygienic) were regarded as possible risk factors for the transmission of (respiratory) infections. Whereas smoking, stagnant water and material used for cooking were hypothesized to be associated with respiratory symptoms of non-infectious nature. We have also included the variable of the participant's membership in an NGO as a proxy variable for better health knowledge and better access to health services, particularly for women.

\section{Statistical analysis}

Various statistical analyses ranging from descriptive analysis to multivariable modelling were performed (IBM SPSS Statistics for Windows, Version 20.0. Armonk, NY: IBM Corp.). For the outcome variable, first, we applied a cross-table analysis and then bi-/ multivariable binary logistic regression models. ${ }^{24}$ Categorical variables were tested using chi-squared tests. Confidence intervals $(95 \%)$ and P-values at the significance level 0.05 are reported.

\section{Ethical Considerations}

No medical equipment or medicine (placebo or drugs) were used in the study. No blood was collected from the respondents. No experiments on humans were conducted. An informed consent was obtained from each participant. All information was anonymous, provided on a voluntary basis and self-reported or selfassessed by the respondents.

\section{Results}

Table 1 and Figures 1 summarize the descriptive statistics of the study sample. The reported three month prevalence of coughs and colds was $21.5 \%(n=1892)$ and of all three symptoms $23 \%(n=1272)$. The mean age of the respondents was 34.4 years.

The average household income per month in the study population was higher than reported in census survey 2005 (17): $35.6 \%$ of the families in our study reported having a household monthly income of maximum 5,000 Taka, which is below the poverty line, compared to more than $90 \%$ of households in the census survey. Yet more than a half of the respondents $(55.3 \%)$ reported a maximum household income of $6,000 \mathrm{Taka} / \mathrm{month}$ in our study.

The prevalence of coughs, colds and fever differed significantly in nine study areas, with the highest 
Table 1: Basic socio-demographic and household-level characteristics of study population $(\mathrm{n}=1893)$

\begin{tabular}{|c|c|}
\hline Variables & N (\%)* \\
\hline \multicolumn{2}{|l|}{ Age (years) } \\
\hline Mean & 34 \\
\hline Standard deviation & 13 \\
\hline \multicolumn{2}{|l|}{ Gender } \\
\hline Female & $987(52.1 \%)$ \\
\hline \multicolumn{2}{|l|}{ Individual income (Bangladeshi Taka) } \\
\hline Median & 3000 \\
\hline Interquartile range & 5000 \\
\hline \multicolumn{2}{|l|}{ Household income (Bangladeshi Taka) } \\
\hline Mean & 6979 \\
\hline Standard deviation & 5160 \\
\hline \multicolumn{2}{|l|}{ No education } \\
\hline Age group 18 to 40 & $1,166(61.6 \%)$ \\
\hline \multicolumn{2}{|l|}{ Type of house } \\
\hline Provisional & $91.4 \%$ \\
\hline \multicolumn{2}{|c|}{ How often is the house area affected by stagnant water } \\
\hline Not every year & $148(7.8 \%)$ \\
\hline At least one time a year & $879(46.4 \%)$ \\
\hline More than one time a year & $318(16.8 \%)$ \\
\hline No stagnant water at all & $546(28.9 \%)$ \\
\hline \multicolumn{2}{|l|}{ Garbage disposal } \\
\hline Collected from home & $141(7.4 \%)$ \\
\hline Dispose near household & $640(33.8 \%)$ \\
\hline Dispose in a bin outside the house & $251(13.3 \%)$ \\
\hline $\begin{array}{l}\text { Dispose in open space outside the } \\
\text { house }\end{array}$ & $861(45.5 \%)$ \\
\hline \multicolumn{2}{|l|}{ Smoking cigarette (yes) } \\
\hline Male & $417(46 \%)$ \\
\hline Female & $47(4.8 \%)$ \\
\hline \multicolumn{2}{|l|}{ Smoking inside home (by sex) } \\
\hline Male & $309(34.1 \%)$ \\
\hline Female & $20(2 \%)$ \\
\hline \multicolumn{2}{|l|}{ Toilet type } \\
\hline Septic tank/modern toilet & $269(14.2 \%)$ \\
\hline Pit/slab latrine & $1130(59.7 \%)$ \\
\hline Open latrine & $174(9.2 \%)$ \\
\hline Hanging latrine & $320(16.9 \%)$ \\
\hline \multicolumn{2}{|c|}{ Use of coil/DDT to protect from mosquitoes } \\
\hline Yes & $617(32.6 \%)$ \\
\hline No & $1270(67.1 \%)$ \\
\hline \multicolumn{2}{|c|}{ Number of persons living with the respondent } \\
\hline $1-2$ persons & $224(11.8 \%)$ \\
\hline 3-4 persons & $694(36.7 \%)$ \\
\hline 5-6 persons & $411(21.7 \%)$ \\
\hline 7 and more persons & $564(29.8 \%)$ \\
\hline \multicolumn{2}{|l|}{ Membership in $N G O$, by sex } \\
\hline Male & $77(8.5 \%)$ \\
\hline Female & $94(9.5 \%)$ \\
\hline \multicolumn{2}{|c|}{ Three-months prevalence of respiratory symptoms } \\
\hline Cough and cold & $407(21.5 \%)$ \\
\hline Fever & $787(41.6 \%)$ \\
\hline Fever and/or cough and/or cold & $292(15.4 \%)$ \\
\hline
\end{tabular}

*Percentages are calculated for the total sample, if not other specified. prevalence in Kunipara bosti (29.1\%) and Bishil and sarag bosti $(26.6 \%)$. Remarkably, the areas were unevenly affected by stagnant water. In Kunipata bosti $26.6 \%$ of the respondents reported being affected by stagnant water more than once in a year, whereas in Adabor bosti this proportion was only $8.6 \%$. The reported frequency of respiratory symptoms among women who were exposed to stagnant water more than once in a year was significantly higher compared to men (Figure 1).

In the bivariable analysis there were no statistically significant differences in the occurrence of respiratory symptoms by individual socio-demographic characteristics like age, education, individual income, marital status and occupation, as well as by smoking behaviour and types of tobacco. However, strong associations were observed between respiratory symptoms and factors related to adverse living conditions and physical environment. Living area and water stagnation were strongly correlated; therefore we chose to exclude the variable 'living area' from further analysis.

Multivariable binary logistic regression models were built and tested for two different dependent variables: "Cough and cold (thanda/kashi)" and the combined variable "Cough and cold (thanda/kashi) and fever (jor)". The included variables were examined for co-linearity, but its statistics did not show any considerable associations (the Variance Inflation Factor (VIF) did not exceed 1.3 in any of the tested models).

Tables 2 and 3 show the major findings of multivariable binary logistic regression analysis for the dependent variable "Cough and cold (thanda/kashi)" (Table 2) and for "Cough and cold (thanda/kashi) and fever (jor)" (Table 3), respectively. Both models showed similar associations between the outcome of interest and selected independent variables.

No associations with age and sex could be observed in the multivariable analysis; yet in the first model men were $24 \%$ less likely to report coughs and colds compared to women (OR:0.76; 95\% CI: 0.59-0.99, Table 2). The likelihood of reporting respiratory symptoms increased with the yearly frequency of stagnant water affecting the house of the respondent. Those respondents whose houses were affected by stagnant water several times a year were three times more likely to report respiratory symptoms (either coughs and colds, OR:2.43; 95\% CI: $1.72-3.42$ or coughs and colds and fever OR:2.97; 95\% CI:1.92-4.59) (Table 2). Besides, the respondents smoking inside their homes were more likely to report coughs and colds and fever (OR:1.54; 95\% CI:1.03-2.30). Finally, using kerosene or heaters as the main cooking material increased the chance of having to report respiratory symptoms compared to gas (OR: 2.20; 95\% CI:1.07-4.54, Table 3).

After stratifying the analysis by gender, the association between having reported coughs and colds or all three symptoms and exposure to stagnant water more than once in a year (recurrent exposure) increased 


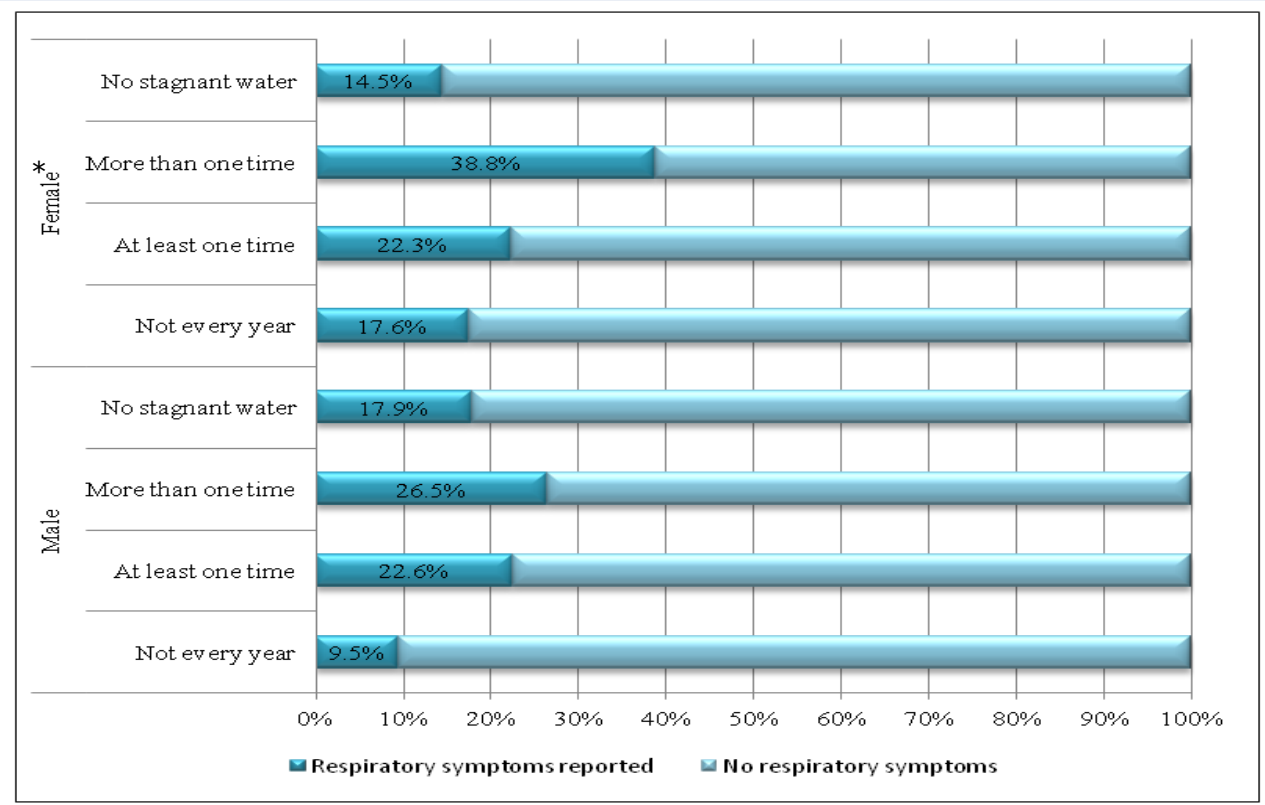

$*$ p-value $<0.0001$ for female

Figure 1: Proportion of female and male respondents with respiratory symptoms in relation to the frequency of exposure to stagnant water $(n=1,892)$

Table 2: Results of multivariable binary logistic regression for the outcome 'Cough and cold' and 'Cough, cold and fever' (adjusted for age, not stratified)

\begin{tabular}{|c|c|c|c|c|c|c|}
\hline \multirow{3}{*}{ Variables } & \multicolumn{6}{|c|}{ Logistic regression } \\
\hline & \multicolumn{3}{|c|}{ Coughs and colds $(\mathrm{N}=1,891)$} & \multicolumn{3}{|c|}{ Coughs, colds and fever $(\mathrm{N}=1,272)$} \\
\hline & Adjusted OR & \multicolumn{2}{|c|}{$95 \% \mathrm{CI}$} & Adjusted OR & \multicolumn{2}{|c|}{$95 \% \mathrm{CI}$} \\
\hline \multicolumn{7}{|l|}{ Gender } \\
\hline Male & 0.76 & 0.59 & 0.99 & 0.75 & 0.55 & 1.04 \\
\hline Female & ref & & & ref & & \\
\hline \multicolumn{7}{|l|}{ Material used for cooking } \\
\hline Gas & ref & & & ref & & \\
\hline Kerosene/ Heater & 1.36 & 0.73 & 2.53 & 2.20 & 1.07 & 4.54 \\
\hline Wood & 0.91 & 0.71 & 1.16 & 1.13 & 0.83 & 1.54 \\
\hline Dry leaves/Other & 0.60 & 0.31 & 1.16 & 0.55 & 0.20 & 1.47 \\
\hline \multicolumn{7}{|c|}{ Number of persons sharing the house } \\
\hline $1-2$ persons & 0.53 & 0.35 & 0.81 & 0.44 & 0.27 & 0.73 \\
\hline 3-4 persons & 0.58 & 0.43 & 0.77 & 0.40 & 0.28 & 0.57 \\
\hline 5-6 persons & 0.80 & 0.58 & 1.09 & 0.62 & 0.42 & 0.91 \\
\hline 7 and more persons & ref & & & ref & & \\
\hline \multicolumn{7}{|c|}{ How often is the house area affected by stagnant water } \\
\hline Not every year & 0.80 & 0.47 & 1.36 & 0.72 & 0.35 & 1.46 \\
\hline At least one time & 1.50 & 1.12 & 2.01 & 2.07 & 1.43 & 3.01 \\
\hline More than one time & 2.43 & 1.72 & 3.42 & 2.97 & 1.92 & 4.59 \\
\hline No stagnant water & ref & & & ref & & \\
\hline \multicolumn{7}{|l|}{ Way of garbage disposal } \\
\hline Collected from home & 0.53 & 0.31 & 0.91 & 0.60 & 0.32 & 1.14 \\
\hline Near household & 0.79 & 0.60 & 1.04 & 0.63 & 0.44 & 0.89 \\
\hline In a bin outside house & 1.08 & 0.76 & 1.53 & 0.82 & 0.52 & 1.27 \\
\hline In open space outside house & ref & & & ref & & \\
\hline \multicolumn{7}{|l|}{ Membership in NGO } \\
\hline Yes & 0.67 & 0.42 & 1.04 & 0.62 & 0.35 & 1.11 \\
\hline No & ref & & & ref & & \\
\hline \multicolumn{7}{|l|}{ Smoke inside the house } \\
\hline Yes & 1.49 & 1.08 & 2.05 & 1.54 & 1.03 & 2.30 \\
\hline No & ref & & & ref & & \\
\hline \multicolumn{7}{|l|}{ House permanent or provisional } \\
\hline Permanent & 0.80 & 0.51 & 1.27 & 0.41 & 0.21 & 0.81 \\
\hline Provisional & ref & & & ref & & \\
\hline
\end{tabular}

South East Asia Journal of Public Health 2013;3(2):58-65 
Table 3: Results of multivariable binary logistic regression for the outcome the outcome 'Cough and cold' and 'Cough, cold and fever' (adjusted for age), only for female participants

\begin{tabular}{|c|c|c|c|c|c|c|}
\hline \multirow{3}{*}{ Variables } & \multicolumn{6}{|c|}{ Logistic regression } \\
\hline & \multicolumn{3}{|c|}{ Cough and cold $(n=986)$, female } & \multicolumn{3}{|c|}{ Cough, cold $\&$ fever $(n=685)$, female } \\
\hline & Adjusted OR & \multicolumn{2}{|c|}{$95 \% \mathrm{CI}$} & Adjusted OR & \multicolumn{2}{|c|}{$95 \% \mathrm{CI}$} \\
\hline \multicolumn{7}{|l|}{$\operatorname{Sex}$} \\
\hline Male & -- & & & -- & & \\
\hline Female & -- & & & -- & & \\
\hline \multicolumn{7}{|l|}{ Material used for cooking } \\
\hline Gas & ref & & & ref & & \\
\hline Kerosene/Heater & 1.96 & 0.82 & 4.70 & 2.26 & 0.80 & 6.35 \\
\hline Wood & 1.03 & 0.72 & 1.47 & 1.18 & 0.76 & 1.81 \\
\hline Dry leaves/Other & 0.66 & 0.29 & 1.52 & 0.534 & 0.147 & 1.93 \\
\hline \multicolumn{7}{|c|}{ Number of persons sharing the house } \\
\hline $1-2$ persons & 0.46 & 0.26 & 0.84 & 0.43 & 0.21 & 0.88 \\
\hline 3-4 persons & 0.60 & 0.40 & 0.89 & 0.38 & 0.24 & 0.61 \\
\hline 5-6 persons & 0.79 & 0.50 & 1.24 & 0.45 & 0.29 & 0.87 \\
\hline 7 and more persons & ref & & & ref & & \\
\hline \multicolumn{7}{|c|}{ How often is the house area affected by stagnant water } \\
\hline More than one time a year & 3.57 & 2.22 & 5.73 & 4.44 & 2.49 & 7.93 \\
\hline Not every year & 1.19 & 0.59 & 2.38 & 0.94 & 0.35 & 2.51 \\
\hline At least one time a year & 1.65 & 1.10 & 2.48 & 2.19 & 1.32 & 3.64 \\
\hline No stagnant water & ref & 2.22 & 5.73 & ref & 2.49 & 7.93 \\
\hline \multicolumn{7}{|l|}{ Way of garbage disposal } \\
\hline Collected from home & ref & & & ref & & \\
\hline Near household & 2.25 & 0.97 & 5.22 & 2.22 & 0.82 & 5.97 \\
\hline In a bin outside house & 3.06 & 1.26 & 7.44 & 2.45 & 0.87 & 7.2 \\
\hline In open space outside house & 2.81 & 1.23 & 6.43 & 3.57 & 1.37 & 9.31 \\
\hline \multicolumn{7}{|l|}{ Membership in $N G O$} \\
\hline Yes & 0.51 & 0.26 & 1.00 & 0.58 & 0.25 & 1.36 \\
\hline No & ref & & & ref & & \\
\hline \multicolumn{7}{|l|}{ Smoke inside the house } \\
\hline Yes & 2.54 & 0.99 & 6.50 & 2.37 & 0.66 & 8.49 \\
\hline No & ref & & & ref & & \\
\hline \multicolumn{7}{|l|}{ House permanent or provisional } \\
\hline Permanent & 0.89 & 0.50 & 1.58 & 0.53 & 0.24 & 1.17 \\
\hline Provisional & ref & & & ref & & \\
\hline
\end{tabular}

dramatically for women (OR:4.44; 95\% CI:2.49-7.93, p-value $<0.0001$, for women, Table 3). Smoking inside the house among women (OR:2.37; 95\% CI:0.66-8.49, $\mathrm{p}$-value $=0.053$, Table 3 ) showed a higher likelihood of respiratory symptoms, although the results were statistically insignificant. Disposal of waste in open spaces outside the house was strongly associated with reporting of respiratory symptoms for women (OR:3.57; 95\% CI:1.37- 9.31). For men (data not shown) the results of multivariable logistic regression did not show any significant associations, except for smoking inside the house and coughs, colds and fever (OR:1.57; 95\% CI:1.03-2.40). Associations between any respiratory symptoms and exposure to stagnant water among men became statistically insignificant.

\section{Discussion}

In our study coughs, colds and fever were highly frequent among urban slums dwellers in Dhaka. Recurrent stagnation of water near the house appeared to be the strongest factor predicting respiratory symptoms, and for women the observed effect was significantly stronger when compared to men.

Other studies have also reported a high frequency of respiratory symptoms among urban slums dwellers. The second most frequently reported disease among slum women was fever, coughs and colds in smaller studies examining the health problems of women in three selected slum areas in Dhaka. ${ }^{12}$ Older age was associated with coughs, colds and fever in an urban livelihood study conducted in Dhaka slums, ${ }^{25}$ and the prevalence of coughs was higher among women compared to men in transitional camps in Sri Lanka. ${ }^{26}$

\section{Interpretation of the results}

Coughs, colds and fever are some of the common symptoms of respiratory diseases. Diseases of the respiratory tract range from acute upper and lower respiratory infections, e.g. common cold and sinusitis or pneumonia and bronchitis, to different chronic 
conditions. ${ }^{27.28}$ Fever itself can be a symptom of a selflimiting illness, like viral acute respiratory infection, as well as of some life-threatening illness, like malaria, meningitis, typhoid and others. ${ }^{29}$ However, some of our findings regarding general respiratory symptoms and their determinants point at potential prevention possibilities and complement the existing evidence.

In our study women were shown to be more vulnerable to respiratory symptoms and some factors were more strongly associated with poor health outcomes than they were for men. In urban slums, women are vulnerable in terms of access to health care services and information, are generally poorer, have less education and poorer health outcomes compared to more affluent urban women and rural women. ${ }^{9,30}$ As women spend more time at home being housewives, their exposure to immediate risk factors surrounding the house is higher.

Recurrent exposure to stagnant water showed the strongest effect on reporting of respiratory symptoms. Stagnant water in urban slums was shown to be an independent factor associated with weaker physical and mental health. ${ }^{31}$ Conceivably there might be other unobserved factors as consequences of standing water, which could have a negative impact on the respiratory health of slum dwellers. Fecal, chemical and/or other contamination of standing bodies of water can, in combination with poor personal hygiene, facilitate transmission of different infections. Water-related vector-borne diseases triggered by breeding mosquitos are further possible causes of common symptoms like fever and coughs. Additionally, waste which is disposed directly near the house or in open spaces can cause significant outdoor and indoor air pollution and garbage rests can also pollute water bodies. People living in damp houses are more likely to suffer from respiratory conditions and be admitted to hospital than those living in well-ventilated buildings. ${ }^{32}$

Our next finding is consistent with the knowledge from other studies showing that smoking inside the home is generally accepted behavior within Bangladeshi households. ${ }^{33,34}$ The respondent's own smoking at home can have negative impact on their own respiratory health as well as on the health of other family members through secondhand or even thirdhand smoke. ${ }^{34,35}$ Moreover, smoking inside the home was shown to be associated with asthma and respiratory symptoms in several studies assessed in the systematic review by Kusel et al. ${ }^{35}$

A guarantee of basic housing conditions for urban slums dwellers as a part of urban planning must be a priority in such countries like Bangladesh, parallel to the improvement of access to affordable health care. Providing urban slum dwellers with necessary treatment but not critically improving their common living conditions would not prevent or solve the problem. ${ }^{36}$ Particularly for women, health education and participation in micro-credit programs can have a positive impact on their awareness about different health issues. ${ }^{37}$ Women exposed to such programs showed better knowledge of acute respiratory infections and their symptoms. ${ }^{37}$ The involvement of health volunteers making primary diagnoses in households based on questioning about respiratory signs and symptoms can also be beneficial for poor areas, as Bangladesh Rural Advance Committee (BRAC) projects demonstrated. ${ }^{38}$

\section{Study limitations}

We have identified the following limitations in our study, caused by the specifics of the design, the settings, population group and other factors.

1. Self-reporting of symptoms. Residents living in disadvantaged urban areas do not routinely seek medical help for unspecific symptoms like coughs and/or colds and fever. The symptoms were not examined or diagnosed by a physician in the majority of cases and might well have been underreported in our study. The study did not measure whether respiratory symptoms were of an infectious or non-infectious nature. Nevertheless, self-reported health was shown to be a valid indicator of morbidity, especially in middle-aged population groups. ${ }^{39}$

2 Recall bias. Respondents could under or overestimate their respiratory symptoms during this period of time.

3. Cross-sectional data. We have used data from the baseline survey and so could only analyse the prevalence data.

3. Due to the limitations of the questionnaire and selfreporting it was not possible to determine whether fever and respiratory symptoms occurred concurrently; yet, if so, then the high incidence of respiratory symptoms and fever could point at, for example, an influenza-like illness.

\section{Conclusion}

We estimated the frequency of the most common respiratory symptoms in urban slums in Dhaka and identified their determinants. The results of our study contribute to the knowledge on morbidity of poor populations in urban slums in Dhaka and give a clue about the factors associated with high frequency of common respiratory symptoms. The exposure of the respondents to stagnant water near their houses and improper garbage disposal is a serious concern since this exposure is recurrent and put urban slum dwellers at permanent risk of their health.

Thus, a consequent reduction of urban poverty and an improvement of elementary housing and living conditions in urban slum settlements, particularly in areas heavily affected by stagnant water and flooding, is likely to have a huge positive impact on the health status of populations of all ages, and particularly vulnerable groups. 


\section{Acknowledgement}

The study in Dhaka, Bangladesh, was conducted with the funding from the German Research Foundation (DFG) in frames of the project INNOVATE under the DFG priority programme 1233 'Megacities Megachallenge: Informal Dynamics of Global Change'.

\section{References}

1. Detels R. The scope and concerns of public health. In: Detels R, Beaglehole R, Lansang MA, Gulliford M, editors. Oxford Textbook of Public Health. 5th ed. New York: Oxford University Press, 2011;3-19.

2. World Bank. Mongolia: Air Pollution in Ulaanbaatar - Initial Assessment of Current Situations and Effects of Abatement Measures. Washington, DC: The International Bank for Reconstruction and Development/World Bank, 2009.

3. Ribeiro SH, Cardoso MR. Air pollution and children's health in Sao Paulo (1986-1998). Soc Sci Med 2003; 57: 2013-22.

4. Cohen AJ, Ross Anderson H, Ostro B, Pandey KD, Krzyzanowski M, Künzli N, et al. The global burden of disease due to outdoor air pollution. J Toxicol Environ Health 2005; 68: 1301-7.

5. McMichael AJ. The urban environment and health in a world of increasing globalization: issues for developing countries. Bull World Health Organ 2000; 78(9): 1117-26.

6. Smith KR, Samet JM, Romieu I, Bruce N. Indoor air pollution in developing countries and acute lower respiratory infections in children. Thorax 2000; 55: 518-32.

7. Unger A, Riley LW. Slum Health: From Under-standing to Action (Essay). PLoS Medicine 2007; 4(10): 1561-66.

8. Riley LW, Ko AI, Unger A, Reis MG. Slum health: diseases of neglected populations. $B M C$ Int Health Hum Rights 2007; 7(1): 2.

9. Sclar ED, Garau P, Carolini G. The 21st Century Health Challenge of Slums and Cities. Lancet 2005; 365(9462): 901-3.

10. Bangladesh Bureau of Statistics (BBS). Statistical Pocketbook of Bangladesh 2005. Dhaka: BBS, 2005.

11. ICDDR,B. MANOSHI Working Paper 09, 2009. http://www.icddrb.org/publications/ doc_download/262-the-perceptions-ofcommunity-groups-to-improve-mnch-in-urbanslums-an-exploratory-case-study-of-korail-slumin-dhaka-manoshi-wp09-2009 (accessed Dec 2013)
12. Democracywatch. Health Problems of Women Living in Slums: A Situation Analysis of Three Selected Slums in Dhaka City (The study is conducted by the 14th batch participants of Gender and Governance Training Program of Democracywatch). Dhaka: Democracywatch, 2014.

13. Ye Y, Zulu E, Mutisya M, Orindi B, Emina J, Kyobutungi C. Seasonal pattern of pneumonia mortality among under-five children in Nairobi's informal settlements. Am J Trop Med Hyg 2009; 81(5): 770-5.

14. Podymow T, Turnbull J, Islam MA, Ahmed M. Health and Social Conditions in the Dhaka Slums. http://www.isuh.org/download/dhaka.pdf (accessed 30 Dec 2013)

15. Emmelin A, Wall S. Indoor Air Pollution: A Poverty-Related Cause of Mortality Among the Children of the World. Chest 2007; 132(5): 1615 -23 .

16. UNICEF. Sanitation, Hygiene and Water Supply in Urban Slums. Factsheet. Dhaka: UNICEF, 2008.

17. Centre for Urban Studies (CUS), National Institute of Population Research and Training (NIPORT), MEASURE Evaluation. Slums of Urban Bangladesh: Mapping and Census, 2005. Dhaka: Bangladesh and Chapel Hill, USA, 2006.

18. Zanuzdana A, Khan M, Kraemer A. Housing satisfaction related to health and importance of services in urban slums: evidence from Dhaka, Bangladesh. Soc Ind Res 2013; 112(1): 163-85.

19. Gruebner O, Khan MMH, Lautenbach S, Mueller D, Kraemer A, Lakes T, Hostert P. A spatial epidemiological analysis of self-rated mental health in the slums of Dhaka. Int J Health Geogr $2011 ; 10(36)$

20. Bartlett JE, Kotrlik JW, Higgins CC. Organizational Research: Determining Appropriate Sample Size in Survey Research. Inform Tech Learn Perform J 2001; 19: 43-50.

21. Baer RD, Weller S, Pachter L, Trotter R, de Alba Garcia JG, Glazer $\mathrm{M}$, et al. Cross-cultural perspectives on the common cold: Data from five populations. Human Organ 1999; 58(3):251-60.

22. Rashid SF, Hadi A, Afsana K, Begum SA. Acute respiratory infections in rural Bangladesh: cultural understandings, practices and the role of mothers and community health volunteers. Trop Med Int Health 2001; 6(4): 249-55.

23. Nizame FA, Nasreen S, Unicomb L, Southern D, Gurley ES, Arman S, et al. Understanding community perceptions, social norms and current practice related to respiratory infection in Bangladesh during 2009: a qualitative formative study. BMC Public Health 2011; 11: 901. 
24. Kleinbaum DG, Kupper LL, Nizam A, Mulle KE. Applied Regression Analysis and Multivariable Methods. $4^{\text {th }}$ ed. Duxbury, USA: Thomson Brooks/Cole, 2008.

25. Pryer JA. Poverty and Vulnerability in Dhaka Slums: The Urban Livelihood Study. Hampshire, England: Ashgate Publishing Limited, 2003.

26. Turner A, Sameera P, Amanda D, Paramjit G. Sri Lankan tsunami refugees: a cross sectional study of the relationships between housing conditions and self-reported health. BMC Int Health Hum Rights 2009; 9: 16.

27. Hamer D, Bhutta Z, Gorbach S. Infectious diseases. In: Detels R, Beaglehole R, Lansang MA, Gulliford M, editors. Oxford Textbook of Public Health. 5th ed. New York: Oxford University Press, 2011.

28. World Health Organization (WHO). Respiratory tract diseases. http://www.who.int/topics/ respiratory tract diseases/en/ (accessed $30 \mathrm{Dec}$ 2013)

29. National Institute of Population Research and Training (NIPORT), Mitra and Associates, and Macro International. Bangladesh Demographic and Health Survey 2007. Dhaka, Bangladesh and Calverton, Maryland, USA: National Institute of Population Research and Training, Mitra and Associates, and Macro International; 2009.

30. Khan MMH, Kraemer A. Socio-economic factors explain differences in public healthrelated variables among women in Bangladesh: A cross-sectional study. BMC Public Health 2008; 8: 254.

31. Khan MMH, Gruebner O, Kraemer A. Is area affected by flood or stagnant water independently associated with poorer health outcomes in urban slums of Dhaka and adjacent rural areas? Nat Hazards 2014; 70:1: 549-65.

32. World Health Organization. Damp and mould. Health risks, prevention and remedial actions. Geneva: World Health Organization, 2009.

33. Abdullah AS, Hitchman SC, Driezen P, Nargis N, Quah AC, Fong GT. Socioeconomic Differences in Exposure to Tobacco Smoke Pollution (TSP) in Bangladeshi Households with Children: Findings from the International Tobacco Control (ITC) Bangladesh Survey. Int $J$ Environ Res Public Health 2011: 8: 842-60.

34. Zafar Ullah AN, Huque R, Akter S, Nasreen S, Akter $\mathrm{H}$, Thomson $\mathrm{H}$, et al. Children's exposure to second-hand smoke at home in Bangladesh: a community survey. BMJ Open 2013;3(11): e003059.

35. Kusel J, Timm B, Lockhart I. The impact of smoking in the home on the health outcomes of non-smoker occupants in the UK. Tob Induc Dis 2013; 11:3.

36. Shetty P. Health care for urban poor falls through the gap. Lancet 2011; 377(9766): 627-8.

37. Hadi A. Integrating prevention of acute respiratory infections with micro-creid programme: experience of BRAC, Bangladesh. Public Health 2002; 116: 238-44.

38. Hadi A. Management of acute respiratory infections by community health volunteers: experience of Bangladesh Rural Advancement Committee (BRAC). Bull World Health Organ 2003; 81: 183-9.

39. Miilunpalo S, Vuori I, Oja P, Pasanen M, Urponen H. Self-rated health status as a health measure: the predictive value of self-reported health status on the use of physician services and on mortality in the working-age population. $J$ Clin Epidemiol 1997; 50(5): 517-28. 